\title{
ANÁLISE DO PROGRAMA MAIS MÉDICOS SOB O VIÉS CONSTITUCIONAL DE POLÍTICA PÚBLICA
}

\section{ANAL YSIS OF THE “MAIS MÉDICOS” PROGRAM UNDER THE CONSTITUTIONAL ASPECTS OF PUBLIC POLICY}

\begin{abstract}
Camila Ferrara Padin
Mestranda em Direito Político e Econômico na Universidade Presbiteriana Mackenzie. Membro do Grupo de Pesquisa "Estado e Economia no Brasil" e projeto de pesquisa "A aparente colisão entre direitos sociais e econômicos". Advogada, graduada em Direito pela Universidade Presbiteriana Mackenzie. E-mail: camila.padin@gmail.com
\end{abstract}

José do Carmo Veiga de Oliveira

Doutor em Direito Político e Econômico, pela Universidade Presbiteriana Mackenzie; Mestre em Direito Processual pela Pontifícia Universidade Católica de Minas Gerais; Especialização em Direito Público pela Faculdade de Direito do Vale do Rio Doce, de Governador Valadares MG; Especialização em Direito Público, pela Faculdade de Direito de Teófilo Otoni e Desembargador aposentado do Tribunal de Justiça de Minas Gerais. Atualmente é Professor da Faculdade de Direito da Universidade Presbiteriana Mackenzie e Professor da Pontifícia Universidade Católica de Minas Gerais.

E-mail: jveigadeoliveira61@gmail.com

Recebido em: 09/04/2018

Aprovado em: 17/08/2018

RESUMO:O presente artigo tem por premissa investigar o modo de atuação do Programa Mais Médicos sob o ponto de vista da estrutura institucional governamental através da utilização do quadro de referência de uma política pública desenvolvido pela Professora Maria Paula Dallari Bucci, a fim de verificar, por meio de método hipotético-dedutivo, se o Programa atingiu os objetivos por ele proposto para maximização do acesso à saúde pública. Para tanto, pretende-se, i) elucidar o enquadramento institucional de uma política pública; ii) entender o momento político em que o Programa foi instituído e iii) analisar as diretrizes do Programa com base na ferramenta pedagógica denominada "quadro de referência" para, então, responder o problema a que artigo se debruça que consiste em verificar em que medida o Programa Mais Médicos promoveu a maximização do acesso a tratamentos médicos e ampliação das vagas de cursos de medicina.

Palavras Chave: políticas públicas. programa mais médicos. quadro de referência de políticas públicas.

ABSTRACT: This article has as premise to investigate the way in which the Mais Médicos Program operates under the governmental institutional structure using the reference framework of a public policy developed by Maria Paula Dallari Bucci, in order to verify, through a hypothetical-deductive method, whether the Program has achieved the goals it proposes to maximize access to public health. To do so, it is intended, i) to elucidate the institutional framework of a public policy; ii) to understand the political momentum in which the Program was established; and iii) to analyze the Program's guidelines on the basis of the pedagogical 
named "frame of reference", in order to answer the problem which is what extent the MaisMédicos Program promoted the maximization of access to medical treatments and the expansion of vacancies in medicine courses.

Key Words: public policy, mais medicos program; framework of public policies.

SUMÁRIO: Introdução; 1. Enquadramento Institucional da Política Pública; 2. Contexto Social e Político do Programa Mais Médicos; 3. Análise das Diretrizes do Programa Mais Médicos sob a ótica do Quadro de Referência de uma Política Pública; 4. Aspectos Críticos do Desenho Jurídico -Institucional; Conclusão; Referências Bibliográficas.

\section{INTRODUÇÃO}

A Constituição Federal Brasileira de 1988 encampou muitas necessidades dos cidadãos que clamavam pela positivação unificada de direitos democráticos e sociais: a saúde pública foi um deles. A Carta Magna estabelece que a saúde é um direito de todos e um dever do Estado e, em razão disso, o Estado passou a ser garantidor da saúde pública mediante a implementação de políticas sociais e econômicas que ampliasse a política setorial pública de saúde capaz de garantir o acesso universal e igualitário às ações e serviços para promoção, proteção e recuperação da saúde da população.

Diante dessa assertiva criou-se a política nacional do Sistema Único de Saúde (“SUS") que, de acordo com o Ministério da Saúde, é um dos maiores sistemas públicos de saúde do mundo (MINISTÉRIO DA SAÚDE, 2016), tendo como principal diretriz formar uma rede de serviços e ações governamentais, regionalizadas e hierarquizadas dentro do território nacional, visando o acesso universal e igualitário da saúde.

Assim, o SUS é considerado uma das maiores políticas públicas do Brasil, pois traduziu um diálogo coletivo, ratificando e unificando os interesses públicos, reconhecidos pelo Direito e resultante de um processo ou do conjunto deles (BUCCI, 2006, p.26). Nessa toada, é importante salientar que a verdadeira política pública é o programa de ação governamental que resulta em um conjunto de processos juridicamente regulados de planejamento, governo, orçamentário, legislativo e administrativo, visando a realização de objetivos socialmente relevantes (BUCCI, 2006).

Ocorre que o SUS não é um programa capaz de sanar todos os problemas da saúde e todas as demandas que os cidadãos enfrentam diariamente com a falta de acesso à saúde pública (IBGE, 2009), tornando-se, portanto, o núcleo central e irradiador de diversas políticas que foram arquitetadas dentro da administração e estatal visando a complementação desse programa e perpetuação do serviço por ele prestado.

A título elucidativo, de acordo com uma pesquisa realizada em 2009, denominada "Estatísticas da Saúde - Assistência Médico-Sanitária" promovida pelo Instituto Brasileiro de Geografia e Estatística (IBGE, 2009), os estabelecimentos privados de saúde são constituídos predominantemente com fins lucrativos $(90,6 \%)$, se comparado com a proporção de estabelecimentos sem fins lucrativos $(9,4 \%)$ e de estabelecimentos com vínculo com o sistema público de saúde (SUS), que em 2005 representavam 30,6\% dos estabelecimentos privados, passando para 27,1\% em 2009 (IBGE, 2009, p. 27).

Diante desse cenário e pretendendo, dentre outros, maximizar o acesso à saúde pela população, a ex-Presidente da República Dilma Rousseff por meio da Medida Provisória $n^{\circ}$ 621, publicada em 8 de julho de 2013, posteriormente regulamentada em outubro do mesmo ano pela Lei $\mathrm{n}^{\circ}$ 12.871, implementou o denominado Programa Mais Médicos ("PMM"), gerando um intenso debate sobre a questão em todas as esferas sociais, políticas e jurídicas.

Segundo suas próprias diretrizes, o Programa Mais Médicos é parte de um esforço do Governo Federal, com apoio de Estados e Municípios, para a melhoria do atendimento aos 
usuários do Sistema Único de Saúde (BRASIL, 2015), e, de acordo com o art. $1^{\circ}$ da Lei $n^{\circ}$ 12.871/13, diminuir a carência de médicos nas regiões prioritárias para o SUS; fortalecer a prestação de serviços de atenção básica em saúde no País e aperfeiçoar médicos para atuação nas políticas públicas de saúde do Brasil.

Assim, da análise dos elementos estruturais adentra-se ao estudo do "quadro de referência de uma política pública" para que seja possível estabelecer quem são os agentes e os elementos que compõem especificamente o Programa Mais Médicos, a fim de se detectar a existência de eventuais gargalos na implementação da medida e questionar se o Programa cumpriu os fins por ele propostos para avanço do acesso à saúde, maximização do acesso a tratamentos médicos, ampliação das vagas de Cursos de Medicina.

Propõe-se investigar a realidade empírica sob a qual o referido Programa foi implementado, trazendo ao debate as dinâmicas traçadas pelo Governo e suas reais contribuições para o acesso à saúde dentro da análise estabelecida pelo "quadro de referência de uma política pública" para, ao final, possibilitar uma conclusão da arquitetura executória deste Programa de ação.

\section{ENQUADRAMENTO INSTITUCIONAL DA POLÍTICA PÚBLICA}

O termo política pública é objeto de diversos estudos jurídicos que visam, em suma, extrair o máximo de seu sentido e alcance dentro do organograma governamental. Celina Souza (SOUZA; 2006) afirma que as últimas décadas registraram o ressurgimento da importância do campo de conhecimento denominado políticas públicas.

Leonardo Secchi (SECCHI, 2014, p. 01) afirma que o termo política pública está vinculado aos conteúdos concretos e simbólicos de decisões políticas e do processo de construção e atuação dessas decisões . Qualquer definição de política pública é arbitrária . Na literatura especializada não há um consenso quanto à definição do que seja uma política pública (SECCHI, 2014, p. 02).

O conceito de políticas públicas e a ideia de desenvolvimento, ligada a uma efetiva construção de direitos sociais, está em constante transformação e seu entendimento no debate jurídico e político oscila de forma pendular conforme cada momento histórico e conjuntura política específica. As políticas públicas são fundamentais para as democracias modernas, porque é essencialmente por meio delas que o Estado ou os Governos entram em ação (DYE, 2009; SOUZA, 2006).

Fábio Konder Comparato (COMPARATO, 2015) define política pública como uma atividade, isto é, um conjunto organizado de normas e atos tendentes à realização de um objetivo determinado. Assim, o Estado, através da atuação governamental, deve ter participação decisiva, incialmente, na formulação de políticas públicas voltadas para a superação das desigualdades, a inclusão social e para a aquisição de direitos (SMANIO, 2015).

Por sua vez, Maria Paula Dallari Bucci (BUCCI, 2006), aborda uma visão institucionalizada de políticas públicas, contemplando não somente o plano micro da sua implementação, como também o seu processo macro de estruturação e organização ${ }^{1}$.

Percebe-se que não existe uma definição linear e imutável de política pública, porém, todas estas têm como premissa básica que o Estado tem um papel determinante no sentido de guiar a sociedade e organizar os recursos postos à sua disposição para a consecução de objetivos juridicamente relevantes (DUARTE, 2015, p. 15). A política pública, de acordo com essa

\footnotetext{
${ }^{1}$ Política pública é o programa de ação governamental que resulta de um processo ou conjunto de processos juridicamente regulados - processo eleitoral, processo de planejamento, processo de governo, processo orçamentário, processo legislativo, processo administrativo, processo judicial - visando coordenar os meios à disposição do Estado e as atividades privadas, para a realização de objetivos socialmente relevantes e politicamente determinados (BUCCI, 2006, p.36).
} 
concepção, está voltada à realização de direitos por meio de arranjos institucionais que se expressam em programas de ação governamental complexos (DUARTE, 2013, p. 18). Elas devem ser vistas como processo ou conjunto de processos que culminam na escolha racional e coletiva de prioridades, para a definição dos interesses públicos reconhecidos pelo Direito (BUCCI, 2002, p.26).

Ocorre que, para o real estudo e entendimento do conceito e diretriz chave de uma política pública, é preciso estudar o processo políti co de tomada de decisões e os requisitos necessários para a sua legitimidade. Há de se levar em consideração as causas (ou fundamentos) e consequências (resultados) da ação governamental (DUARTE, 2013, p.18). Esta tipologia vê a política pública como um ciclo deliberativo, formado por vários estágios e constituindo um processo dinâmico e de aprendizado (SOUZA, 2006).

O Professor Francisco Fonseca trabalha a temática sob a perspectiva de processo de decisão política ${ }^{2}$. Desta feita, a política pública não tem um conceito estanque e imutável, porque encampa uma relação enredada e interdependente composta de diversos elementos que lhes dão forma e possibilidade de transcendência do plano meramente formal para o material.

Portanto, não há como pensar em política pública sem pensar no engendramento administrativo ao qual determinado programa pertence. Analisar seus elementos sem incorporar a ideia de eles pertencerem a um ciclo de atuação não permitirá ao intérprete extrair a verdadeira proposta irradiadora daquela política, portanto, o processo de elaboração de políticas também é conhecido como ciclo de políticas públicas que é , portanto, um esquema de visualização e interpretação que organiza a vida de um programa de ação em fases sequenciais e interdependentes (SECCHI, 2012).

Desta breve análise, conclui-se, de forma a abrir espaço ao tópico seguinte, que um estudo voltado ao arranjo jurídico-institucional de uma política pública é o que possibilita entender o porquê de algumas políticas sociais não efetivarem os fins pelos quais são propostas ou ainda o porquê de não resistirem a fragmentação estatal. Estudar a criação e implantação de um programa permite que se trace um panorama detalhado de quais são as eventuais falhas que apresentou ou quais foram as medidas de sucesso a fim de se utilizar como paradigma para implementação de programa diverso.

\section{CONTEXTO SOCIAL E POLÍTICO DO PROGRAMA MAIS MÉDICOS}

Notadamente marcada pela necessidade de ampliação de diretrizes de acesso à saúde pública, o fim da década de 1970 e toda a década de 1980 foram fundamentais para a saúde pública no Brasil devido ao movimento de Reforma Sanitária Brasileira (MACEDO, ALCÂNTARA, ANDRADE. FERREIRA, 2015). A percepção da política como pulverizada e passível de desagregação de benefícios foi dificultada pela visibilidade da agenda da Reforma Sanitária. As inovações da política de saúde dos anos de 1980 foram tomadas como tipo ideal de mudança na política social no contexto da transição democrática pós-1985. (ROSARIO, 1996).

Em 1987 implantou-se o Sistema Unificado e Descentralizado de Saúde - SUDS (FUNDAÇÃO OSWALDO CRUZ, 2016), o primeiro passo para a unificação do acesso à saúde pública, sendo sucedido pela Constituição de 1988 que estabeleceu a universalidade do acesso a tal direito, transformando o Estado em agente garantidor mediante a implementação de políticas sociais e econômicas que alcançassem a política setorial pública de saúde capaz de garantir o

\footnotetext{
2 um processo de decisão política que se materializa em objetivos com resultados esperáveis, normalmente vinculados à transformação de uma dada realidade, com vetores distintos, e que envolvem: a) técnicos estatais e não governamentais, burocratas e políticos (tomadores de decisão); b) atores distintos (com "recursos de poder" assimétricos), cenários e conjunturas (por vezes voláteis); c) capacidade e viabilidade de o Estado disponibilizar recursos orçamentários, humanos, legais e logísticos; d) mecanismos de mensuração dos resultados. (FONSECA, 2013, p. 405).
}

Revista de Direito Brasileira | São Paulo, SP | v. 20 | n. 8 | p. 429-447 |Mai./Ago. 2018 
acesso universal e igualitário às ações e serviços para promoção, proteção e recuperação da saúde da população.

Através da promulgação da Lei Orgânica da Saúde (Lei no 8080/90), que dispunha sobre as condições para a promoção, proteção e recuperação da saúde, além da organização e funcionamento dos serviços correspondentes (FUNDAÇÃO OSWALDO CRUZ, 2016), foi instituída a política nacional do Sistema Único de Saúde que, de acordo com o Ministério da Saúde, é um dos maiores sistemas públicos de saúde do mundo. Ele abrange desde o simples atendimento ambulatorial até o transplante de órgãos, garantindo acesso integral, universal e gratuito para toda a população do País (MINISTÉRIO DA SAÚDE, 2016). Portanto, o SUS tem como principal diretriz formar uma rede de serviços e ações governamentais, regionalizadas e hierarquizadas dentro do território nacional, visando o acesso universal e igualitário da saúde.

Ocorre que o SUS não é um programa capaz de sanar todos os problemas da saúde pública do País e todas as mazelas que os cidadãos enfrentam diariamente com a falta de acesso à saúde pública (IBGE, 2009). Diante disso, o SUS se tornou um grande centro de irradiação de diversas políticas públicas complementares que foram arquitetadas sob o cerne desse Programa, visando a complementação e perpetuação do serviço por ele prestado.

$\mathrm{O}$ cenário em que o PMM foi inserido pode ser traduzido pela pesquisa sobre a Demografia Médica no Brasil de 2015 (DEMOGRAFIA MÉDICA NO BRASIL, 2015) que constatou que o Brasil contava em outubro de 2015 com 399.692 médicos e uma população de 204.411.281 habitantes, o que corresponde à razão de 1,95 médicos por 1.000 habitantes ${ }^{3}$.

O estudo constatou ainda que há uma tendência de maior concentração de médicos em serviços privados, cujo atendimento é formado por pacientes particulares ou conveniados a planos de saúde (DEMOGRAFIA MÉDICA NO BRASIL, 2015).

Além deste cenário estatístico, o PMM foi instituído em meio a uma crise política instaurada no Brasil marcada por diversas manifestações sociais de descontentamento político. A mobilização dos cidadãos nas ruas, levada a cabo por meios eletrônicos de comunicação social, particularmente as redes sociais, influenciaram enormemente a agenda política dos governos em todas as suas instâncias: federal, estaduais e municipais (PIMENTEL e SILVEIRA, 2013).

Dessa forma, temas como melhorias na saúde tornaram-se pauta nos diversos meios de comunicação de massa e nas redes sociais, contribuindo para que o Governo identificasse uma janela de oportunidade e lançasse o Programa Mais Médicos (MACEDO, ALCÂNTARA, ANDRADE. FERREIRA, 2015).

Através de um pronunciamento em rede nacional, a então Presidente da República lançou o $\mathrm{PMM}^{4}$.

Assim, por meio da Medida Provisória $n^{\circ}$ 621, publicada em 8 de julho de 2013 (BRASIL, 2013), sendo posteriormente regulamentada em outubro do mesmo ano pela Lei $\mathrm{n}^{\circ}$ 12.871, o Programa Mais Médicos foi criado, estabelecendo, em suma, algumas diretrizes de atuação, sendo elas a ampliação de vagas aos Cursos de Medicina; ampliação das Unidades Básicas de Saúde e migração de médicos estrangeiros para municípios brasileiros com menor acesso à saúde.

\footnotetext{
${ }^{3}$ Destes médicos, $21,6 \%$ dos médicos trabalham exclusivamente no setor público e $26,9 \%$ só atuam no setor privado. Os demais, 51,5\%, atuam nas duas esferas, a pública e a privada. Considerando a atuação exclusiva mais a sobreposição (atuação concomitante nos dois setores), $78,4 \%$ dos médicos trabalham no setor privado e $73,1 \%$ trabalham no setor público. Dentre os $73,1 \%$ dos médicos que trabalham no setor público $(21,6 \%$ deles exclusivamente), mais da metade (51,5\%) trabalha em hospitais (DEMOGRAFIA MÉDICA NO BRASIL, 2015) ${ }^{4}$ Todos nós, brasileiras e brasileiros, estamos acompanhando, com muita atenção, as manifestações que ocorrem no país. Elas mostram a força de nossa democracia e o desejo da juventude de fazer o Brasil avançar. [...]O foco será: [...] trazer de imediato milhares de médicos do exterior para ampliar o atendimento do SUS. Precisamos de suas contribuições, reflexões e experiências, de sua energia e criatividade, de sua aposta no futuro e de sua capacidade de questionar erros do passado e do presente. (PLANALTO, 2013).
} 
Conclui-se, portanto, que o Programa foi implementando em meio a uma série de manifestações políticas e sociais, muito embora exista discussões acerca da articulação desse Programa antes desse período de crise, além da escassez de atendimento público no Brasil, principalmente nas regiões destacadas como sendo as mais carentes e de difícil acesso. O cenário político e social do PMM era temerário, todavia, acreditou-se que o Programa pudesse suplantar a carência de atendimento público e acalentar os ânimos sociais que clamavam pela majoração do acesso à saúde.

\section{ANÁLISE DAS DIRETRIZES DO PROGRAMA MAIS MÉDICOS SOB A ÓTICA DO QUADRO DE REFERÊNCIA DE UMA POLÍTICA PÚBLICA}

Nem sempre uma política pública atinge os fins propostos, tornando-se uma medida ineficaz e de alcance limitado. Isto posto, a Professora Maria Paula Dallari Bucci criou uma ferramenta chamada "quadro de referência de uma política pública" (BUCCI, 2015) que possibilita um estudo detido e fragmentado do programa de ação governamental. Sem o emprego de tal ferramenta, as possibilidades analíticas sobre a dimensão jurídica das políticas públicas serão sempre fragmentadas e limitadas (BUCCI, 2015). Em outras palavras, o método está na base tanto do conhecimento como da ação organizada por meio do direito (BUCCI, 2015).

De acordo com o proposto pelo quadro de referência (BUCCI, 2015) busca-se a sintetização do caráter sistemático que articula os elementos mais importantes que integram a política pública. Assim, para que possa estabelecer uma crítica contundente ao Programa, passase à análise detida de cada item que compõe o referido quadro, abaixo especificados.

\section{A. BASE NORMATIVA (BASE JURÍDICA FORMAL)}

De acordo com Maria Paula Bucci apontar a norma que institui o Programa e as disposições mais importantes específicas para o seu funcionamento (BUCCI, 2015). A norma principal, cujo suporte pode ser de hierarquia variada se caracteriza por conferir caráter sistemático ao Programa, articulando seus diversos elementos e os vários focos de competência (BUCCI, 2015).

A Medida Provisória $n^{\circ} 621$ foi convertida na Lei $n^{\circ} 12.871 / 13$, na qual institui o Programa Mais Médicos com a finalidade de formar recursos humanos na área médica para o Sistema Único de Saúde (BRASIL, 2013), alterando as Leis $n^{\circ} 8.745$ de 9 de dezembro de $1993^{5}$, e a de $\mathrm{n}^{\mathrm{O}}$ 6.932, de 7 de julho de $1981^{6}$.

Ademais, o PMM foi instituído visando formar recursos humanos na área médica para o Sistema Único de Saúde a fim de diminuir a carência de médicos nas regiões prioritárias para o SUS.

Em complementação à lei ordinária que instituiu o PMM, tem-se o Decreto ${ }^{\circ}$ 8.126, de 22 de outubro de 2013, que dispõe sobre a emissão do registro único e da carteira de identificação para os médicos intercambistas participantes do Programa Mais Médicos para o Brasil; o Decreto $n^{\circ}$ 8.081, de 23 de agosto de 2013, que altera o Decreto $n^{\circ}$ 8.040, de 8 de julho de 2013, que institui o Comitê Gestor e o Grupo Executivo do Programa Mais Médicos, para dispor sobre o pedido de inscrição do registro provisório de médico.

\footnotetext{
${ }^{5}$ Dispõe em seu artigo $1^{\circ}$ que para atender à necessidade temporária de excepcional interesse público, os órgãos da Administração Federal direta, as autarquias e as fundações públicas poderão efetuar contratação de pessoal por tempo determinado, nas condições e prazos previstos nesta Lei.

${ }^{6}$ Dispõe sobre as atividades do médico residente e dá outras providências.
}

Revista de Direito Brasileira | São Paulo, SP | v. 20 | n. 8 | p. 429-447 |Mai./Ago. 2018 


\section{B. DESENHO JURÍDICO-INSTITUCIONAL}

A identificação da base normativa do Programa é mais viável quando se consegue descrever a sua organização numa visão macro (BUCCI, 2015). Assim, passa-se à análise dos principais agentes institucionais e suas competências, atribuições e responsabilidades sobre o funcionamento do Programa, tanto no interior do aparelho governamental, como fora dele (BUCCI, 2015).

Os atores relevantes em um processo de política pública são aqueles que têm capacidade de influenciar, direta ou indiretamente, o conteúdo e os resultados da política pública. (SECCHI, 2012).

\section{I - AGENTES GOVERNAMENTAIS}

De acordo com a Lei $n^{\circ}$ 12.871/13 que institui o Programa Mais Médico, ficou estabelecido que a coordenação do Programa ficaria a cargo dos Ministérios da Educação e da Saúde, que disciplinariam, por meio de ato conjunto dos Ministros de Estado da Educação e da Saúde, a forma de participação das instituições públicas de educação superior e as regras de funcionamento do Projeto, incluindo a carga horária, as hipóteses de afastamento e os recessos previstos no artigo $13^{\circ}$ da referida lei.

A autorização para o funcionamento de curso de graduação em Medicina, por instituição de educação superior privada, seria precedida de chamamento público, e caberia ao Ministro de Estado da Educação dispor sobre a pré-seleção dos Municípios para a autorização de funcionamento de Cursos de Medicina que estariam sujeitos à efetiva implantação das diretrizes curriculares nacionais definidas pelo Conselho Nacional de Educação (CNE), conforme artigos $3^{\circ}$ e $4^{\circ}$ da Lei $12.871 / 13$.

As instituições de educação superior responsáveis pela oferta dos Cursos de Medicina e dos Programas de Residência Médica poderiam firmar Contrato Organizativo da Ação Pública Ensino-Saúde com os Secretários Municipais e Estaduais de Saúde, na qualidade de gestores, com a finalidade de viabilizar a reordenação da oferta de cursos e vagas de Residência Médica e todas as hipóteses abaixo destacadas encontram-se nos artigos $12^{\circ} ; 23^{\circ}, 31^{\circ}$; e 33 da Lei 12.871/13.

Ao Conselho Regional de Medicina (CRM) competiria a área de atuação, a relação de médicos intercambistas participantes do Programa Mais Médicos para o Brasil e os respectivos números de registro único.

Para execução das ações previstas no Programa, os Ministérios da Educação e da Saúde poderiam firmar acordos e outros instrumentos de cooperação com organismos internacionais, instituições de educação superior nacionais e estrangeiras, órgãos e entidades da administração pública direta e indireta da União, dos Estados, do Distrito Federal e dos Municípios, consórcios públicos e entidades privadas, inclusive com transferência de recursos.

Os Ministros de Estado da Educação e da Saúde poderiam editar normas complementares para o cumprimento do disposto na lei em comento.

A Advocacia-Geral da União atuaria, nos termos do art. 22, da Lei $n^{\circ}$ 9.028/95, na representação judicial e extrajudicial dos profissionais designados para a função de supervisor médico e de tutor acadêmico prevista nos incisos II e III, do art. 15.

\section{II - AGENTES NÃO GOVERNAMENTAIS}

Para a execução de qualquer programa governamental há necessidade expressa que agentes fora do aparelho governamental atuem de forma completar, visando a consecução das diretrizes impostas pelo Programa (BUCCI, 2015). 
No Programa em comento, que envolve primordialmente o serviço de agentes fora da aparelhagem estatal, é imprescindível que todas as incumbências estejam expressas. A compreensão de quais são os principais interessados, os protagonistas e possíveis antagonistas do Programa, as forças sociais que explicitamente (ou de forma menos visível) lho sustentam confere maior profundidade à análise (BUCCI, 2015).

Dito isto, os principais agentes, fora o aparelho governamental, que atuam de forma completar, visando a consecução das diretrizes impostas pelo Programa são, essencialmente, os médicos dele participantes. Ficou estabelecido no artigo $15^{\circ}$ da Lei $12.871 / 13$ que integram o Programa Mais Médicos o médico participante, que será submetido ao aperfeiçoamento profissional supervisionado; o supervisor, profissional médico responsável pela supervisão profissional contínua e permanente do médico e o tutor acadêmico, docente médico que será responsável pela orientação acadêmica.

Além destes, outros agentes não governamentais que são aptos ao destaque são: a Empresa Brasileira de Serviços Hospitalares (EBSERH) e o Hospital de Clínicas de Porto Alegre (HCPA) autorizados a conceder bolsas para ações de saúde, a ressarcir despesas, a adotar outros mecanismos de incentivo a suas atividades institucionais e a promover as ações necessárias ao desenvolvimento do Programa Mais Médicos, observado o artigo $26^{\circ}$ da Lei no 12.550/11.

Por fim, destacam-se as instituições de educação superior responsáveis pela oferta dos cursos de Medicina como outro agente não governamental responsáveis pela consecução de atividades previstas no Programa.

\section{DIMENSÕES ECONÔMICO-FINANCEIRAS}

Os recursos financeiros vinculados ao Programa são um dado da maior relevância (BUCCI, 2015).

Do exposto no artigo 30 e seus incisos subsequentes dispostos na Lei 12.871/13 fica estabelecido que o quantitativo dos integrantes dos projetos e programas de aperfeiçoamento de que trata o Programa observará os limites dos recursos orçamentários disponíveis. O quantitativo de médicos estrangeiros no Programa Mais Médicos para o Brasil não poderá exceder o patamar máximo de $10 \%$ (dez por cento) do número de médicos brasileiros com inscrição definitiva nos CRMs.

As despesas decorrentes da execução dos projetos e programas previstos correrão à conta de dotações orçamentárias destinadas aos Ministérios da Educação, da Defesa e da Saúde, consignadas no orçamento geral da União. Além disso, caberá à União conceder ajuda de custo destinada a compensar as despesas de instalação do médico participante, que não poderá exceder a importância correspondente ao valor de 3 (três) bolsas-formação, além de custear despesas com deslocamento dos médicos participantes e seus dependentes legais, conforme dispuser ato conjunto dos Ministros de Estado do Planejamento, Orçamento e Gestão e da Saúde.

Por fim, o SUS terá o prazo de 5 (cinco) anos para dotar as unidades básicas de saúde com qualidade de equipamentos e infraestrutura, a serem definidas nos planos plurianuais, observados os artigos $26^{\circ}$ e $27^{\circ}$ da Lei $12.871 / 13$.

Conclui-se, portanto, que os gestores dos planos orçamentários são os Ministérios da Educação, da Defesa e da Saúde, consignadas no orçamento geral da União.

O Tribunal de Contas da União (UNIÃO, 2015) observou que, considerando os gastos com tutores e supervisores e os custos do curso a distância ministrado para esses médicos, o dispêndio total da especialização somente para os médicos estrangeiros, nos três anos de projeto, ficará em R \$ 242.782.748,72. Isso quer dizer que o Governo Federal investirá mais de R\$240 milhões no prazo de três anos para especializar profissionais que, ao final do projeto, têm grandes 
chances de deixar o País e não aplicar aqui os conhecimentos adquiridos ( $\mathrm{TC} \mathrm{n}^{\circ}$ 005.391/2014- 8, peça 171, p. 40) (UNIÃO, 2015).

\section{ESTRATÉGIA DE IMPLANTAÇÃO}

Nesse ponto, o objetivo é descrever, com base nas fontes oficiais, qual é o movimento pretendido ou esperado pelo gestor público que protagoniza a instituição do Programa (BUCCI, 2015).

De acordo com as diretrizes divulgadas no site oficial do Programa Mais Médicos (BRASIL, 2015), o movimento esperado por essa política pública é registrado da seguinte forma:

Além de levar mais médicos para regiões onde há escassez ou ausência desses profissionais, o programa prevê, ainda, mais investimentos para construção, reforma e ampliação de Unidades Básicas de Saúde (UBS), além de novas vagas de graduação, e residência médica para qualificar a formação desses profissionais (BRASIL, 2015).

Em suma, podem-se destacar dois pontos centrais esperados pelo Programa: o primeiro voltado a expansão da graduação e da residência médica no Brasil, sendo a meta do Governo Federal criar 11,5 mil novas vagas de graduação e 12,4 mil vagas de residência até 2017 (BRASIL, 2015). A segunda diretriz central do Programa é o fortalecimento da Atenção Básica do País que é a porta de entrada do SUS, fomentando a diminuição nas esperas pelo atendimento básico de saúde pelos cidadãos (BRASIL, 2015).

\section{E. FUNCIONAMENTO EFETIVO DO PROGRAMA}

Compreendido o desenho ideal do Programa, poderá o analista confrontá-lo com o seu funcionamento real, numa visão panorâmica (BUCCI, 2015). Desta visão panorâmica é possível estabelecer os reais avanços ou retrocessos enfrentados pelo Programa, considerando todos os dados levantados e todas as análises feitas tanto no plano micro, quanto no macro da política pública.

O PMM, como já visto ao logo do estudo, possui um endereço eletrônico próprio, criado pelo Governo Federal para divulgar resultados, tirar dúvidas, informar as legislações pertinentes e principalmente mostrar o cenário do Programa em termos de avanço na sua execução. Assim, dessa fonte específica de informação, no que compete exclusivamente aos atendimentos médicos, expõe-se que:

O Programa Mais Médicos está completando dois anos de existência. Nesse período, garantiu 18.240 médicos em 4.058 municípios (73\% dos municípios brasileiros) e nos 34 distritos de saúde indígenas ${ }^{7}$.

Ademais, considerando a segunda diretriz central do Programa, a expansão da graduação e da residência médica no Brasil recebeu abordagem específica do Governo Federal ${ }^{8}$.

Em fonte adversa de informação, por meio da Solicitação de Informação ao Tribunal de Contas da União $\mathrm{n}^{\mathbf{o}}$ 2, de 2015, de autoria do Deputado Federal Betinho Gomes, que foi

\footnotetext{
${ }^{7}$ Disponível em: http://maismedicos.gov.br/conheca-programa.

${ }^{8}$ Já em 2014 foram aprovadas as Novas Diretrizes Curriculares para os Cursos de Medicina, que tem até 2018 para adequarem seus currículos a ela. Até 2013, as 27 capitais do país ofereciam 8.858 vagas em cursos de graduação em medicina, enquanto todos os demais municípios brasileiros (mais de 5.000 cidades) tinham 8.612 vagas. Agora, a realidade é outra: o número de vagas nas capitais subiu para 10.637 e, no interior, 14.522. O programa Mais Médicos já criou 4.742 vagas de residência em todo o país (BRASIL, 2015).
}

Revista de Direito Brasileira | São Paulo, SP | v. 20 | n. 8 | p. 429-447 |Mai./Ago. 2018 
encaminhada pelo Deputado Federal Eduardo Cunha, Presidente da Câmara dos Deputados à época, em atendimento a uma decisão da Mesa Diretora daquela Casa, pode-se extrair conclusões diversas daquelas apresentadas no endereço eletrônico do PMM.

O documento encaminhado faz referência ao TC $n^{\circ} 027.492 / 2013-3$, o qual aborda o acompanhamento do Programa Mais Médicos, e solicita que sejam encaminhadas as seguintes informações: a) quais foram os principais avanços e problemas observados na auditoria operacional realizada no Programa Mais Médicos; e b) quais medidas foram requeridas do gestor do Programa para sanar as irregularidades observadas (UNIÃO, 2015).

Algumas conclusões apresentadas nesse Relatório quanto à supervisão das atividades dos médicos participantes são registradas abaixo ${ }^{9}$. Outrossim, apresentou falhas quanto à tutoria das atividades dos médicos participantes ${ }^{10}$, além de que foi feita análise acerca da distribuição geográfica dos médicos do Programa ${ }^{11}$.

Quanto às ações de avaliação e monitoramento foram observadas fragilidades nos impactos ocasionados pelo Projeto. Constatou-se que não houve uma avaliação para checar se os Municípios substituíram médicos que compunham anteriormente as equipes de atenção básica por médicos participantes do Programa. (UNIÃO, 2015). A Equipe de Auditoria comprovou que dos 2.143 municípios que receberam profissionais do Programa Mais Médicos no ano de $2013\left(1^{\circ}\right.$ e $2^{\circ}$ ciclos), pelo menos 127 deles $(5,93 \%$ do total) possuíam, em abril de 2014 , menos equipes de atenção básica (TC nº 005.391/2014-8, peça 171, p. 29) (UNIÃO, 2015).

Em relação aos 1.174 municípios que receberam médicos nos $1^{\circ}$ e $2^{\circ}$ ciclos do Programa Mais Médicos, a Equipe de Auditoria fez constatações no TC n ${ }^{\circ}$ 005.391/2014-8, peça 167, pp. 50 e $51^{12}$. Interessante relato foi registrado pelo Tribunal de Contas da União (2015) relativo à avaliação dos dados disponíveis acerca da variação da produção da atenção básica apenas em atendimento nos municípios participantes do Programa ${ }^{13}$.

\begin{abstract}
${ }^{9}$ Foram observados os seguintes problemas: a) o número de médicos supervisores cadastrados à época da fiscalização era insuficiente. $\mathrm{Na}$ amostra analisada, 31,73\% dos médicos participantes não possuíam supervisores indicados no sistema informatizado utilizado pela UNA-SUS (TC $n^{\circ} 005.391 / 2014-8$, peça 171, p. 14); b) havia médicos supervisores que desempenhavam outras atividades com carga horária semanal superior a cem horas, além da supervisão exercida no projeto, o que poderia comprometer o trabalho de supervisão ( $T C$ n ${ }^{\circ}$ 005.391/2014-8, peça 171, pp. 17 e 18);

c) as avaliações encaminhadas pelos supervisores eram pouco focadas em aspectos clínicos e se referiam mais ao controle de absenteísmo, à estrutura das unidades, à composição das equipes, aos serviços de apoio e aos aspectos educacionais ( $\mathrm{TC} \mathrm{n}^{\circ} 005.391 / 2014-8$, peça 171, p. 18) (UNIÃO, 2015).

${ }^{10}$ a) havia uma quantidade insuficiente de tutores (TC $n^{\circ} 005.391 / 2014-8$, peça 171 , pp. 18 e 19); b) alguns tutores tinham sob sua responsabilidade mais de cem médicos participantes, sendo que havia sido fixado um quantitativo máximo de cem médicos para cada tutor (TC n ${ }^{\circ} 005.391 / 2014-8$, peça 171, pp. 18 e 19); c) o Plano de Trabalho elaborado pelo tutor, apresentava estrutura bastante simplificada e superficial, incompatível com o disposto no art. 14, II, da Portaria Interministerial MS/MEC n ${ }^{\circ} 1.369 / 2013$ ( $\mathrm{TC} \mathrm{n}^{\circ} 005.391 / 2014-8$, peça 171, p. 20); d) os tutores, de modo geral, não forneciam orientação acadêmica adequada aos médicos participantes. (UNIÃO, 2015)
\end{abstract}

${ }^{11}$ Foram observados os seguintes problemas: a) falhas na distribuição de médicos do Projeto Mais Médicos para o
Brasil, caracterizadas pelo não atendimento a munícipios com carências e dificuldades (TC $\mathrm{n}^{\circ} 005.391 / 2014-8$, peça
171 , p. 27); b) 592 dos municípios listados na Portaria SGTES/SAS no $3 / 2013$, considerados prioritários por serem
carentes, não haviam recebido nenhum médico do projeto, o que equivale a $26 \%$ dos municípios dessa relação (592
de 2.282). (UNIÃO, 2015).
${ }^{12}$ Em 161 desses municípios ( $14 \%$ da amostra), houve redução do número de médicos; Em outros 239 municípios
(20\% da amostra), não houve nem aumento nem redução do número de médicos, mesmo após a chegada dos novos
profissionais, o que é um forte indício de que houve a substituição dos médicos contratados anteriormente pelos
municípios por profissionais que participam do Projeto Mais Médicos; em 70 municípios $(6 \%$ da amostra), foi
impossível fazer essa análise, pois as bases de dados encontravam-se incompletas (UNIÃO, 2015).
${ }^{13}$ a) com base nos dados relativos a 1.837 municípios dos 2.116 municípios que receberam médicos nos $1^{\circ}$ e $2^{\circ}$ ciclos
do Projeto Mais Médicos, constatou-se que em $25 \%$ ( 466 de 1.837$)$ desses municípios, houve uma diminuição da
produção de consultas médicas na atenção básica; em $1 \%$ (23 de 1.837$)$ desses municípios, não houve variação
percentual;- nos municípios em que não houve aumento da produção, foram alocados 1.157 médicos nos $1^{\circ}$ e $2^{\circ}$

Revista de Direito Brasileira | São Paulo, SP | v. 20 | n. 8 | p. 429-447 |Mai./Ago. 2018 
Constatou ainda que alguns Municípios visitados durante a Auditoria não estavam cumprindo suas obrigações no que tange à oferta de moradia para os médicos participantes do Programa e à garantia de alimentação adequada e água potável para esses profissionais (UNIÃO, 2015).

Por fim, a unidade técnica destacou resultados positivos que foram detectados na referida Auditoria ${ }^{14}$.

Com base nos dados acima destacados, serão estabelecidos a seguir comentários críticos acerca do desenho jurídico institucional do Programa, bem como elaborar considerações finais acerca da sua efetividade.

\section{ASPECTOS CRÍTICOS DO DESENHO JURÍDICO-INSTITUCIONAL}

Após uma análise detida dos aspectos micro e macro presentes no organograma institucional do Programa Mais Médicos, serão tecidos a seguir alguns comentários desse desenho jurídico institucional delimitando eventuais gargalos e problemáticas encontrados.

Destaca-se, a priori, que um dos maiores problemas enfrentados pelo Programa foi a ausência de interlocução com as frentes de medicina, quais sejam, Conselhos e Associações, impondo-lhes obrigações sem, contudo, tê-los permitido participar do processo de estruturação do Programa.

Tal assertiva se confirma pela propositura da Ação Direta de Inconstitucionalidade $\left(\mathrm{N}^{\circ}\right.$ 3451/2014 - ASJCONST/SAJ/PGR) em que figuraram no polo ativo a Associação Médica Brasileira (AMBR) e o Conselho Federal de Medicina (CFM). Essa ação demonstra o descontentamento das entidades frente a imposição dessa política pública.

Indignados com a deflagração desse Programa, os requerentes alegaram que a medida provisória que instituiu o PMM incorreu em: ausência dos requisitos de relevância e urgência; violação aos direitos sociais dos trabalhadores; princípio do concurso público; dispensa de comprovação de proficiência na língua portuguesa; dentre outros.

De igual forma, o STF já se manifestou a respeito do Programa Mais Médicos nas ADI 5035 e 5037, ajuizadas contra a MP 621/2013. Naqueles questionamentos, discutiu-se as arguições como a imposição de servidão civil aos estudantes do curso de Medicina; limitação territorial do exercício da profissão, precarização nas relações de trabalho; exercício ilegal da Medicina e necessidade de revalidação do diploma.

Ademais, pode-se perceber que o arcabouço normativo que envolve o PMM ainda é muito escasso, destacando-se a Medida Provisória nº 621 que foi convertida em Lei $\mathrm{n}^{\circ} 12.871$,

ciclos (TC 005.391/2014-8, peça 167, pp. 58 e 59);b) as causas para a diminuição da quantidade de consultas em $25 \%$ dos municípios participantes do projeto $\left(1^{\circ}\right.$ e $2^{\circ}$ ciclo) foram de difícil determinação, tendo em vista o escopo limitado desta auditoria. Ressalta-se que a redução ou a manutenção do número de consultas caracteriza o não fortalecimento da prestação de serviços de atenção básica em saúde no País, o que vai de encontro ao disposto no art. $1^{\circ}$, I, da Lei que instituiu o Programa Mais Médicos e caracteriza o não atingimento do objetivo principal desse programa (TC 005.391/2014-8, peça 171, p. 36) (UNIÃO, 2015).

${ }^{14}$ a) com base nos dados relativos a 1.837 dos 2.116 municípios que receberam médicos nos $1^{\circ}$ e $2^{\circ}$ ciclos, apurou-se que houve um aumento de $33 \%$ na média mensal de consultas. (TC 005.391/2014-8, peça 171, p. 35); b) 130 Unidades Básicas de Saúde (UBS) foram visitadas durante a auditoria. Em 52 dessas unidades foram coletadas informações sobre a evolução das consultas médicas e em 29 delas foram obtidos dados sobre a evolução das visitas realizadas pelos médicos que ali trabalhavam. (TC 005.391/2014-8, peça 171, pp. 36 e 37); d) do acima exposto, conclui-se que houve uma melhora no acesso à atenção básica após a chegada dos médicos do projeto (TC $\mathrm{n}^{\circ}$ 005.391/2014-8, peça 171, p. 38); e) Até o encerramento da auditoria, haviam sido alocados 13.790 médicos do Projeto Mais Médicos para o Brasil em 3.756 municípios e 33 Distritos Sanitários Especiais Indígenas (DSEI), localizados em todas as 27 unidades federadas ( $\mathrm{TC} \mathrm{n}^{\circ}$ 005.391/2014-8, peça 171, p. 43). (UNIÃO, 2015). 
que instituiu o Programa Mais Médicos e não se detecta uma gama normativa detalhada que conecte os diversos entes governamentais envolvidos.

Além disso, o PMM institui mecanismos de articulação assimétricos em que os agentes envolvidos não concordavam com as ideias propostas, haja vista a propositura da ação direta de inconstitucionalidade. Sob esse prisma pode-se afirmar que o PMM também é falho, pois um dos principais agentes institucionais que é o Conselho Regional de Medicina não concordava com as suas competências, atribuições e responsabilidades quanto ao funcionamento do Programa.

Percebeu-se uma concentração muito grande de incumbências aos Ministérios da Saúde e Educação que reúnem toda a gestão do programa no Brasil e irradiam todas as medidas a serem tomadas. Essa assimetria frente aos demais órgãos gerou lentidão na sanção e efetivação das medidas, dado ao cúmulo de trabalho e, também, trouxe certa negligência frente a uma fiscalização mais detida da implementação das medidas em caráter nacional.

Outro ponto que deve ser levado em consideração para a análise do Programa é a participação da mídia e da população que protagonizaram as manifestações sociais de julho de 2013. A mídia foi um importante mecanismo de articulação popular, representando os grupos de interesse ou grupos de pressão. Os grupos de interesse influenciaram a tomada de decisões, pressionando direta ou indiretamente os agentes implementadores quando da efetivação das políticas públicas (SECCHI, 2012). Os grupos de pressão utilizaram vários meios para fazer seus objetivos serem acolhidos no processo de elaboração como marchas ou paradas (SECCHI, 2012) que foi o caso do que ocorreu especificamente com a publicação do PMM.

A mídia, muitas vezes arraigada em posicionamentos políticos diversos e tendenciosos, foi responsável pela veiculação das manifestações em todo o Brasil e também por mobilizar os setores sociais que não tinham contato com as redes sociais das quais se tornaram um canal de convergência para a realização dos atos de manifestação nas ruas.

Destaca-se também as reivindicações do outro grupo de interesse, os médicos. O principal aspecto do Programa que foi alvejado de críticas é a dispensa do Revalida (Exame Nacional de Revalidação de Diplomas Estrangeiros) para médicos estrangeiros que ocupam as vagas criadas pelo Programa nos lugares do País pré-estabelecidos como sendo uma zona de carência de profissionais marcados principalmente pelas regiões Norte e Nordeste.

A maioria dos críticos apontam que a dispensa da revalidação dos diplomas dos médicos estrangeiros contratados, impossibilita a aferição da capacidade do profissional para exercício da medicina no País, deixando seus futuros pacientes à mercê da capacidade técnica daquele profissional que pode ser aquém do esperado.

Outra crítica bastante relevante no meio jurídico é a questão do eventual vínculo empregatício que os médicos estrangeiros estariam submetidos quando da contratação para participação no Programa. De acordo com o artigo 17, da Lei $\mathrm{n}^{\mathbf{0}} 12.871 / 13$, as atividades desempenhadas no âmbito do PMM não criam vínculo empregatício de qualquer natureza. $\mathrm{O}$ argumento utilizado para sua legalidade é que os profissionais participam de um intercâmbio de estudantes e não da ocupação de posto de trabalho propriamente dito.

Ocorre que muitos críticos, principalmente os médicos que vieram participar do Programa, afirmam que essa não caracterização de vínculo empregatício é falaciosa, visto que no próprio contrato de trabalho (Contrato Individual para la Prestación de Servicios Profesionales y Tecnicos en el Exterior) há previsão expressa de relação de trabalho:

Mediante el presente Contrato CSMC estabelece la relación de trabajo com el PROFESSIONAL DE LA SALUD CUBANO, em virtude de los servicios que éste brindará en el território de la República Federativa del 
Brasil, bajo los términos y condiciones que mediante este Contrato se convienen 15

Não cabe no presente estudo levantar a questão de existência ou não de vínculo empregatício, porém, serve apenas para demonstrar outro argumento que a comunidade médica questionou no momento da implementação do Programa, visto que o Governo Brasileiro deixa expressamente claro que não há vínculo trabalhista, mas no contrato assinado com a Sociedade Mercantil de Serviços Médicos Cubana há essa previsão.

Outrossim, cabe questionar a eficácia de um dos pilares do PMM, a expansão da graduação e da residência médica no Brasil. O Tribunal de Contas da União (UNIÃO, 2015 - TC 022.106/2015-4) acolheu a representação das Faculdades Integradas do Extremo Sul da Bahia (UnesulBahia), em que afirmava a existência de possíveis irregularidades no edital aberto em junho de 2014 e que previa a criação 2460 vagas de Medicina em 39 Municípios do País.

O Tribunal decidiu pelo prosseguimento do certame, muito embora tenha avaliado que a política educacional implantada não traz expansão de mercado para oferta de cursos de Medicina, pois, faria apenas uma redistribuição na oferta dos Cursos, com sua interiorização. Colaciona-se abaixo o trecho do voto em questão:

A política educacional implantada não traz expansão de mercado para oferta de cursos de Medicina. Na melhor das hipóteses, se presta apenas a promover uma redistribuição na oferta dos cursos, com sua interiorização. A respeito, transcrevo trecho constante do documento intitulado "Programa Mais Médicos - Dois Anos: Mais Saúde Para Os Brasileiros", da Secretaria de Gestão do Trabalho e da Educação em Saúde (disponível em Acesso em: 15 jun 2016): "Além de o Brasil apresentar uma proporção insuficiente de médicos para as necessidades da população, esses profissionais estão mal distribuídos no território”. (UNIÃ̃, 2015 TC 022.106/2015-4)

Outra questão que mostra um gargalo na execução do Programa é a constatação pelo TCU (TC nº 005.391/2014-8, peça 171, p. 38-39) que alguns Municípios visitados durante a auditoria não estavam cumprindo suas obrigações no que tange à oferta de moradia para os médicos participantes do projeto e a garantia de alimentação adequada e água potável para esses profissionais. Em 05 dos 41 Municípios visitados, o fornecimento de alimentação aos médicos do Programa estava em desacordo e em 04 a oferta de moradia a médicos participantes não atendia ao disposto no mesmo normativo.

Por fim, concluindo a análise em foco e questionando o segundo pilar determinado pelo PMM que era a distribuição de médicos para as regiões ditas carentes de atendimento de saúde, o TCU (TC nº 005.391/2014-8, peça 171, p. 27) verificou que há falhas na distribuição de médicos do Programa Mais Médicos para o Brasil, caracterizadas pelo não atendimento a Municípios com carências e dificuldades para reter médicos integrantes de Equipes da Saúde da Família (ESF).

Nos 592 dos Municípios listados na Portaria SGTES/SAS n $3 / 2013$, considerados prioritários por serem carentes, não haviam recebido nenhum médico do Programa, o que equivale a 26\% dos Municípios dessa relação (592 de 2.282). Os demais 1.690 Municípios da lista, que haviam sido atendidos pelo Programa, receberam 4.524 médicos (até 12/5/2014), o que representa $33 \%$ de todos os médicos locados até a época da fiscalização.

\footnotetext{
15 Tradução Livre: "Pelo presente Acordo CSMC estabelece a relação de trabalho com o profissional de saúde cubano, em virtude dos serviços que venham a conceder no território da República Federativa do Brasil, nos termos e condições previstas no presente Acordo são acordadas" disponível em https://oncubamagazine.com/wmag/wpcontent/uploads/2015/03/contrato-individual-colaboradores-cubanos-mais-medicos-y-suplemento.pdf, acesso em 16.04.2018
} 
Dessa forma, conclui-se que o PMM não cumpriu com o quanto proposto em liame normativo, pois, muito embora tenham sido constatados alguns resultados positivos, eles não justificam a carência de interlocução dos entes governamentais para a execução do Programa que o torna uma política pública de alcance limitado.

Há também uma falha na articulação dos elementos mais importantes que integram essa política pública, com destaque maior ao escasso arcabouço normativo e mecanismos jurídicos de articulação ineficientes que influenciaram o funcionamento efetivo do Programa.

As demasiadas críticas midiáticas que se coadunam com as críticas dos opositores do Governo, não corroboram com a aceitação ampla desse Programa de ação, havendo ainda uma resistência da população para a aceitação dessa política sendo fomentada por diversas críticas relacionadas ao possível enquadramento dos médicos estrangeiros como empregados; as ausências do Revalida e de condições indignas a que os médicos participantes do Programa são submetidos constatadas pelo TCU.

Conclui-se, portanto, que o Programa, sob a ótica do quadro de referência de uma política pública, apresenta uma considerável falha organizacional em sua trama executória o que fomenta um resultado ainda inexpressivo no que tange os seus pilares básicos de irradiação. Ademais, há que se pontuar que as pesquisas de efetividade desse Programa ainda são superficiais, sendo o Tribunal de Contas da União a principal fonte de informações técnicas e analíticas.

\section{CONCLUSÃO}

Consta expressamente do texto constitucional promulgado em 05 de outubro de 1988, já emendado por quase uma centena de vezes, que "A República Federativa do Brasil, formada pela união indissolúvel dos Estados e Municípios e do Distrito Federal, constitui-se em Estado Democrático de Direito e tem como fundamentos", expressamente prescrito no inciso III do seu artigo $1^{\circ}$, "a dignidade da pessoa humana".

É evidente que sob a perspectiva "cidadã" não se poderia ter como ponto de partida uma afirmativa tão contundente como essa, estabelecendo um primado de superlativa relevância quando se avalia sob a perspectiva do que realmente interessa e sob a ótica arguta do legislador constituinte que pretendia, a todo instante, restabelecer valores que, na avaliação daqueles a quem se incumbiu de elaborar a nova ordem constitucional, deveria primar pela alta respeitabilidade ao povo brasileiro.

Todavia, apesar de esse dispositivo não se encontrar entre aqueles que foram alterados pela quase centena de emendas constitucionais, muitas delas carecedoras de uma análise mais aprofundada para efeito de se preservar os direitos fundamentais, e outros que apesar de infensos a essa gana reformista, acabaram por passar por ao largo dessas investidas. No entanto, em sua aplicabilidade em termos de métodos e formas estabelecidos pelo seu intérprete, nada preocupado com os aspectos discricionários de seus próprios atos ou medidas "de governo" e não de "ordem constitucional", emprestou ao texto constitucional do artigo 196, da CR/88 a sua "melhor interpretação", com o propósito evidente e indesculpável de buscar uma aplicação capaz de superar uma questão de ordem absolutamente constitucional para se atender uma ótica distorcida da realidade brasileira.

Referimo-nos, pois, a uma questão meramente ideológico-partidária e nada constitucional sob a perspectiva do Texto Magno Brasileiro, diante de um povo carente, sob todos os aspectos. Assim, sob a análise do ponto de vista "discricionário", houve quem entendesse e fez por adotar esse princípio diante de uma "preferência nada constitucional", para efeito de atender outras "discricionariedades", e, por isso, chegou-se à apreciação da Corte Máxima deste País, mediante o ajuizamento de ações diretas de inconstitucionalidades. 
O fato é que boa parte da população brasileira se encontra submetida a uma carência imensa na área de saúde, apesar da "importação de mão-de-obra médica" para aplicá-la num programa de políticas públicas rotulado de "Programa Mais Médicos", que a despeito dos contornos de legalidade, fere mortalmente princípios comezinhos estabelecidos pela CR/88 e, sobretudo, pelo Direito Administrativo Pátrio.

Não se pode conceber um Programa que deveria estar voltado para a adoção de política pública dentro de um contexto de atendimento a uma carência notória e reclamada por anos pela população brasileira sem que, efetivamente, fosse procedida a uma análise pragmática da conhecida e tão decantada "relação custo-benefício".

É inquestionável que diante da submissão dessa mão-de-obra especializada não se poderia abandonar a possibilidade de uma licitação ampla para que houvesse a melhor escolha dentro de padrões ético-legais e não ideológicos, considerando-se que esse "programa" já estava sendo alvo de trabalhos que vinham sendo desenvolvidos desde o ano de 2012 e que, em 2013, após as graves manifestações das ruas, seus clamores foram "ouvidos e atendidos" e, então, implementado sob o fundamento de se tratar de uma "política pública".

Todavia, a falta de critérios mais claros e esclarecidos à população, sobretudo, no que tange ao idioma pátrio da mão-de-obra especializada, no sentido de se fazer o paciente compreendido pelo profissional e o profissional também compreendido pelo paciente, numa via de verdadeira mão dupla, gerou também, sob o matiz da norma constitucional, graves distorções soante o fundamento insculpido no inciso III, do artigo $1^{\circ}$ da Carta Magna.

Deve-se considerar que, se num primeiro instante proporcionou-se um aumento de oferta de médicos, de outro se abandonou o que poderia constituir um grande avanço para a busca de solução de um ponto de suma importância e que é reclamado desde muito tempo: a restituição, ao Estado, do investimento que se faz (ou que se fazia) às universidades públicas e, aqui, sob especial enfoque quanto aos Cursos de Medicina, que poderiam, com grande margem de segurança, estabelecer uma reciprocidade em termos de retribuição para que nossos jovens médicos, bem formados, naturalmente, pudessem estar a serviço da população carente, mediante justa remuneração, em lugares onde desde sempre esse ressentir é notório e consta de um silêncio ensurdecedor de parte de nossas autoridades político-administrativas, por um período mínimo equivalente, quem sabe, à três quartos (3/4) da duração do seu curso e respectiva residência médica.

Por isto é de se ver que a citação trazida ao exórdio deste trabalho, de autoria de um grande constitucionalista alemão - Konrad Hesse -, mostra que "a força normativa da Constituição não reside, tão-somente, na adaptação inteligente a uma dada realidade". Ela deve e precisa ser aplicada a uma realidade efetiva para que possa surtir efeitos positivos e atender aos princípios e valores que ela própria estabelece para que seja fonte de resultados palpáveis e concretos em favor do povo que elegeu seus representantes esperançosos de que seriam alcançados por uma administração pública de forma legítima e legitimada pelo escrutínio eleitoral ${ }^{16}$.

No entanto, o que se constata é que, por todos os argumentos e fundamentos já declinados na análise do Programa Mais Médicos, de fato, e de direito, não se atentou às normas constitucionais e administrativas, no que pertine às políticas públicas e, por isso mesmo, deve-se atentar para as disposições constitucionais que se encontram à mercê de todos os cidadãos

\footnotetext{
${ }^{\mathbf{1 6}}$ Embora a Constituição não possa, por si só, realizar nada, ela pode impor tarefas. A Constituição transforma-se em força ativa se essas tarefas forem efetivamente realizadas, se existir a disposição de orientar a própria conduta segundo a ordem nela estabelecida, se, a despeito de todos os questionamentos e reservas provenientes dos juízos de conveniência, se puder identificar a vontade de concretizar essa ordem. (A Força Normativa da Constituição KONRAD HESSE, tradução e notas de Gilmar Mendes, pág. 12, disponível em http://www.geocities.ws/bcentaurus/livros/h/hessenpdf.pdf).
} 
brasileiros, mormente o texto insculpido no inciso LLXXIII, do artigo $5^{\circ}$, da CR/88 ${ }^{17}$, quando trata da ação popular, que se destina, entre outros aspectos, produzir, mediante o exercício da jurisdição, a anulação de ato lesivo ao patrimônio público e, especificamente, quando ferir a moralidade administrativa, ficando o autor em caso de objetivo altruístico, pautado em inequívoca boa-fé, isento de custas judiciais e de ônus de sucumbência. Ademais disso, o dever de reparar o erário pelos graves prejuízos financeiros causados aos Brasileiros, agentes de elevada contribuição tributária.

Não se pode ainda desconsiderar que o artigo 37, inciso II $^{18}$, da Lei Maior, ao estabelecer normas a respeito do acesso e investidura em cargo ou emprego público sempre dependente de concurso público de provas ou de provas e títulos. Excluiu-se, portanto, brasileiros que poderiam se interessar por um possível certame para o preenchimento de vagas para o exercício médico em qualquer parte do País, numa concorrência com mão-de-obra estrangeira, com a qual fez o normativo constar que em relação a eles não se constituiria qualquer vínculo empregatício...

Portanto, há questões que precisam ser mais bem esclarecidas nesse episódio do atendimento médico à nossa população carente, sofrida e que continua, em grande parte, desassistida dos mais mínimos preceitos que encarecem a melhor aplicação de um dos fundamentos da República Federativa do Brasil: a dignidade da pessoa humana. Isso também se aplica aos próprios profissionais cubanos que aqui se encontram e em muitos dos casos sem o mínimo de infraestrutura até mesmo para sua própria moradia, sendo igualados àqueles que estão assistindo no seu cotidiano profissional.

Há tempo para todo propósito debaixo do céu e dentre eles, segundo o autor de Eclesiastes, tempo de falar, de ouvir e de calar. Este último é chegado, mas, não sem antes, uma última citação de Konrad Hesse:

Concluindo: pode-se afirmar que a Constituição converter-se-á em força ativa se fizerem presentes na consciência geral — particularmente, na consciência dos principais responsáveis pela ordem constitucional —, não só a vontade de poder (Wille zur Macht), mas também a vontade de Constituição (Wille zur Verfassung)". (KONRAD HESSE, 1991).

\section{REFERÊNCIAS BIBLIOGRÁFICAS}

BRASIL. GOVERNO FEDERAL. Mais Médicos: Conheça o Programa. 2016. Disponível em: <http://maismedicos.gov.br/conheca-programa>. Acesso em: 01.03.2018.

Lei $\mathrm{n}^{\mathrm{o}}$ 12.871, de 10 de outubro de 2013. Institui o Programa Mais Médicos, altera as Leis no 8.745, de 9 de dezembro de 1993, e no 6.932, de 7 de julho de 1981, e dá outras providências. Disponível em: <http://www.planalto.gov.br/ccivil_03/_Ato2011-2014/2013/Lei/ L12871.htm>. Acesso em: 01.03.2018.

MINISTÉRIO DA SAÚDE. (Comp.). Programa Farmácia Popular do Brasil. 2016. Disponível em: <http://portalsaude.saude.gov.br/index.php?option=com_content\&view=article $\& \mathrm{id}=9296 \&$ Itemid=478 $>$. Acesso em: 01.03.2018.

\footnotetext{
${ }^{17} \mathrm{LXXIII}$ - qualquer cidadão é parte legítima para propor ação popular que vise a anular ato lesivo ao patrimônio público ou de entidade de que o Estado participe, à moralidade administrativa, ao meio ambiente e ao patrimônio histórico e cultural, ficando o autor, salvo comprovada má-fé, isento de custas judiciais e do ônus da sucumbência;

${ }^{18} \mathrm{II}$ - a investidura em cargo ou emprego público depende de aprovação prévia em concurso público de provas ou de provas e títulos, de acordo com a natureza e a complexidade do cargo ou emprego, na forma prevista em lei, ressalvadas as nomeações para cargo em comissão declarado em lei de livre nomeação e exoneração;
} 
. PORTAL DO PLANALTO. (Comp.). Programa de rádio "Café com a Presidenta", com

a Presidenta da República, Dilma Rousseff. 2016. Disponível em: http://www2 .planalto.gov.br/acompanhe-o-planalto/cafe-com-a-presidenta/cafe-com-a-presidenta_/programade-radio-201 ccafe-com-a-presidenta201d-com-a-presidenta-da-republica-dilma-rousseff-92.

Acesso em: 15 nov. 2016.

. Portaria Interministerial MS/MEC n 1.369 , de 08 de julho de 2013. Dispõe sobre a implementação do Projeto Mais Médicos Para o Brasil. Disponível em: https://sistemas.mre.gov .br/kitweb/datafiles/Miami/en-us/file/Portaria Interministerial n 1369.pdf. Acesso em: 01.03.2018.

BUCCI, Maria Paula Dallari (org.). Políticas públicas - reflexões sobre o conceito jurídico. São Paulo: Saraiva, 2006.

Direito Administrativo e Políticas Públicas, São Paulo: Saraiva, 2002.

Quadro de Referência de uma Política Pública. Primeiras linhas de uma visão jurídicoinstitucional. In: SMANIO, Gianpaolo Poggio; BERTOLIN, Patrícia Tuma; BRASIL, Patrícia Cristina (org.). O direito na fronteira das políticas públicas, São Paulo: Páginas \& Letras Editora e Gráfica, 2015.

MAGAZINE, Cuba. contrato individual para la prestación de servicios profesionales y tecnicos en el exterior. Disponível em: http://oncubamagazine.com/wmag/wpcontent/uploads/2015/03/contrato-individual-colaboradores-cubanos-mais-medicos-ysuplemento.pdf. Acesso em 02.03.2018.

DUARTE, Clarice Seixas. O Ciclo das Políticas Públicas. In: SMANIO, Gianpaolo Poggio; BERTOLIN, Patrícia Tuma Martins (Org.). O Direito e as Políticas Públicas no Brasil. São Paulo, Atlas, 2013, pp. 16-43.

Para Além da Judicialização: a necessidade de uma nova forma de abordagem das Políticas Públicas. In: SMANIO, Gianpaolo Poggio; BERTOLIN, Patrícia Tuma; BRASIL, Patrícia Cristina (org.). O direito na fronteira das políticas públicas. São Paulo: Páginas \& Letras Editora e Gráfica, 2015.

DWORKIN, Ronald. Levando os direitos a sério. São Paulo: Martins Fontes: 2007.

DYE, Thomas. Mapeamento dos modelos de análise de políticas públicas. In Políticas Públicas e Desenvolvimento. Bases Epistemológicas e Modelos de Análise. (Francisco G. Heidemann, José Francisco Salm, orgs.). 2a. ed. Brasília: Editora UnB, 2006, pp. 99-12

ESCOLA NACIONAL DE SAÚDE PÚBLICA SERGIO AROUCA - Fundação Oswaldo Cruz Histórico da Saúde Pública. Disponível em: http://www.ensp.fiocruz.br/portal-ensp/historico-dasaude, acesso em 02.03.2018.

ESTATÍSTICAS da saúde: assistência médico-sanitária 2009. Rio de Janeiro: IBGE, 2009. Disponível em: http://biblioteca.ibge.gov.br/biblioteca-catalogo?view=detalhes\&id=246754. Acesso em: 02.03.2018. 
FEDERAL, Governo - Entenda o SUS, disponível em http://portalsaude.saude.gov.br/ index.php/cidadao/entenda-o-sus. Acesso em 20.04.2018.

FONSECA, Francisco. Dimensões críticas das políticas públicas. Cad. EBAPE. BR, v. 11, n. 3, p. 402-418, set/nov. 2013.

GIRALDI, Renata. Brasil trará seis mil médicos cubanos para atender moradores de áreas carentes. Agência Brasil, 6 de maio, 2013, Notícias Saúde. Disponível em: http://memoria.ebc.com.br/agenciabrasil/noticia/2013-05-06/brasil-trara-6-mil-medicos-cubanospara-atender-moradores-de-areas-carentes. Acesso em: 01.05.2018.

KONRAD, Hesse. A Força Normativa da Constituição, tradução e notas de Gilmar Ferreira Mendes, AS Fabris Editor, pág. 12, 1991, disponível em http://www.geocities.ws/bcentaurus/livros/h/hessenpdf.pdf).

INSTITUTO BRASILEIRO DE GEOGRAFIA E ESTATÍSTICA. Estatísticas da saúde: assistência médico-sanitária 2009. Rio de Janeiro: IBGE, 2009. Disponível em: http://biblioteca. ibge.gov.br/biblioteca-catalogo?view=detalhes\&id=246754. Acesso em: 02.05.2018

PARTIDO DOS TRABALHADORES (Brasil). Nossa história. 2016. Disponível em: http://www.pt.org.br/nossa-historia. Acesso em: 09.05.2018.

PIMENTEL, T.; SILVEIRA, S. A. Cartografia de espaços híbridos: as manifestações de junho de 2013, Interagentes, 11 de jul. 2013, disponível em http://www.cartapotiguar.com.br /2013/07/31/cartografia-de-espacos-hibridos-as-manifestacoes-de-junho-de-2013/. Acesso em: 09.05.2018.

ROSÁRIO, Nilson do. Inovação Política, Distributivismo e Crise: A Política de Saúde nos Anos 80 e 90. Rio de Janeiro, v. 39, n. 3, p. , 1996 . Disponível em <http://www.scielo.br/ scielo.php?script=sci_arttext\&pid=S00112581996000300007\&lng=en\&nrm=iso $>$. Acesso em: 09.05.2018.

SCHEFFER, M. et al, Demografia Médica no Brasil 2015. Departamento de Medicina Preventiva, Faculdade de Medicina da USP. Conselho Regional de Medicina do Estado de São Paulo. Conselho Federal de Medicina. São Paulo: 2015.

SECCHI, Leonardo. Políticas Públicas - Conceitos, Esquemas de Análise, Casos Práticos. Cengage Learning Editores, 09/2012. E-book. Acesso em: 09.05.2018.

2016.

. Políticas Públicas. Cengage Learning Editores,2014, ed. 2a . E-book. Acesso em: 11 nov.

SMANIO, Gianpaolo Poggio. Cidadania e Políticas públicas. In: SMANIO, Gianpaolo Poggio; BERTOLIN, Patrícia Tuma; BRASIL, Patrícia Cristina (org.). O direito na fronteira das políticas públicas, São Paulo: Páginas \& Letras Editora e Gráfica, 2015. p. 4.

SMANIO, Poggio; BERTOLIN, Patrícia Tuma (Orgs.). O Direito e as políticas públicas no Brasil. São Paulo: Atlas, 2013. E-book disponível em: https://integrada.minhabiblioteca.com.br/ \#/books/9788522484072/. Acesso em: 09.05.2018 
SOUZA, Celina. Políticas Públicas: uma revisão da literatura. Sociologias, Porto Alegre, v. 8, n. 16, p. 20-45, jul/dez. 2006.

UNIÃO, Tribunal de Contas da União (TCU). Auditoria operacional: Solicitação do Congresso Nacional. Pedido de informações sobre os principais problemas e avanços detectados no programa mais médicos e sobre as medidas corretivas determinadas ou recomendadas pelo TCU. TC $\mathrm{n}^{\circ}$ 005.762/2015-4. Disponível em: <https://contas.tcu.gov.br/juris/SvlHighLight?key= 41434f5244414f2d434f4d504c45544f2d31343633383433\&sort=RELEVANCIA\&ordem=DESC \&bases=ACORDAO-COMPLETO; $\&$ highlight $=\&$ posicaoDocumento=0\&numDocumento $=1 \&$ totalDocumentos $=1>$. Acesso em: 09.05.2018 